\title{
Semantic interference and associative facilitation from words presented in rapid serial visual presentation
}

\author{
Alison L. Morris ANd Mary L. Still \\ Iowa State University of Science and Technology, Ames, Iowa \\ Catherine L. Caldwell-Harris \\ Boston University, Boston, Massachusetts \\ AND \\ Miranda D. AtKinson \\ Iowa State University of Science and Technology, Ames, Iowa
}

\begin{abstract}
Semantic interference in picture naming is readily obtained when categorically related distractor words are displayed with picture targets; however, this is not typically the case when both primes and targets are words. Researchers have argued that to obtain semantic interference for word primes and targets, the prime must be shown for a sufficient duration, prime processing must be made difficult, and participants must attend to the primes. In this article, we used a novel procedure for prime presentation to investigate semantic interference in word naming. Primes were presented as the last word of a rapid serial visual presentation stream, with the target following 600-1,200 msec later. Semantic interference was observed for categorically related targets, whereas facilitation was found for associatively related targets.
\end{abstract}

The semantic relatedness paradox refers to the finding that a semantic relationship between a distractor and a tobe-named target sometimes facilitates and sometimes interferes with naming (Neumann, 1986, as cited in Bloem $\&$ La Heij, 2003). For example, the naming of a picture of a banana is significantly slower in the context of the word pear than in the context of the word desk; however, if both items are words, the usual finding is either a null effect or minimal facilitation for naming in related in comparison with unrelated contexts (for reviews, see Hutchison, 2003, and Lucas, 2000). Making the word-naming task more difficult by degrading the target tends to increase semantic facilitation effects (Neely, 1991), but does not produce interference. On the basis of these results, it would be tempting for one to conclude that the naming of word targets with categorically related word primes does not produce semantic interference effects, because word naming can often be performed quickly and independently of semantic processing.

This conclusion would be premature, since a recent study has demonstrated semantic interference using word primes and targets in a naming task. Wentura and Frings (2005, Experiment 4) degraded the primes by rapidly alternating them with a random-letter mask so that most participants could not reliably identify the primes, even though the total prime duration was $143 \mathrm{msec}$. Primes were category names (e.g., FRUIT); targets were either highdominance (e.g., apple) or low-dominance (e.g., mango) exemplars. The target immediately followed the prime. A significant semantic interference effect $(21-26 \mathrm{msec})$ was found for low-dominance category exemplars; this effect was found regardless of the level of prime identification. Thus, semantic interference can be demonstrated in a word-naming task when the prime is severely degraded.

However, degrading the prime may be necessary-but not sufficient-for producing semantic interference in word naming. Masked priming studies typically use short duration primes (less than $70 \mathrm{msec}$ ) and usually result in small amounts of facilitation for categorically related prime-target pairs (see, e.g., Perea \& Gotor, 1997). As noted by Wentura and Frings (2005), prime awareness and prime duration are confounded in masked priming studies. A longer-duration prime that is difficult to identify may be required to produce semantic interference. Computational models of speech production may help us to better understand why this is the case.

One such model is the conceptual selection model (CSM; Bloem, van den Boogaard, \& La Heij, 2004). The basic architecture is shown in Figure 1. The CSM accounts for picture-word interference as follows: When the task is to name a picture and ignore a categorically related word, the word activates its lexical node directly, whereas the pic- 


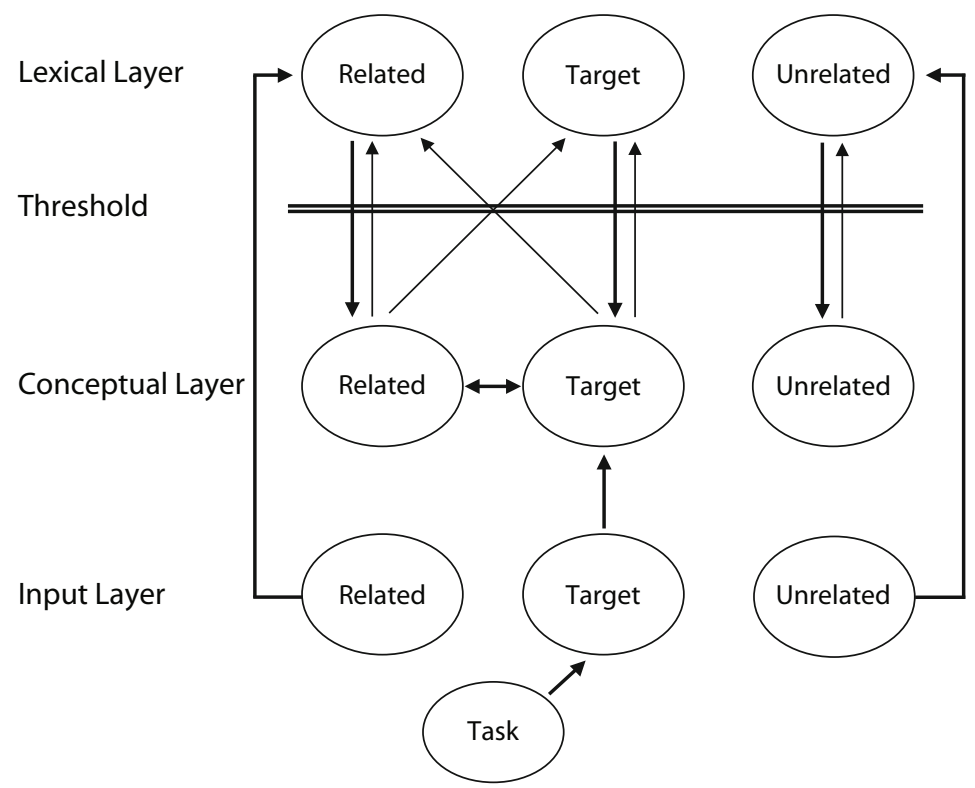

Figure 1. This figure illustrates how a picture target and word distractor would interact in the conceptual selection model. Thick lines indicate strong connections; thin lines indicate weaker connections. A threshold between the conceptual and lexical nodes allows only strong activation from the conceptual level to spread to the lexical level. The input node sends picture information directly to the target's conceptual node and word information directly to the distractor's lexical node. Additional activation is added to the target's conceptual node from the task node. Activation spreads to related nodes in the conceptual layer; activation from the target's conceptual node is able to cross the threshold and activate its lexical node as well as semantically related lexical nodes, resulting in an increase in lexical competition. From "Semantic Facilitation and Semantic Interference in Word Translation: Implications for Models of Lexical Access in Language Production," by I. Bloem and W. La Heij, 2003, Journal of Memory \& Language, 48, p. 478, copyright 2003 by Elsevier, and from "Time-Course Analysis of Semantic and Orthographic Context Effects in Picture Naming," by P. A. Starreveld and W. La Heij, 1996, Journal of Experimental Psychology: Learning, Memory, \& Cognition, 22, p. 903, copyright 1996 by the American Psychological Association. Adapted with permission.

ture activates its conceptual node, subsequently spreading activation to related conceptual nodes, including that of the distractor word. Activation from the picture's conceptual node-with the added boost from the "task" nodeexceeds the threshold and spreads to the picture's lexical node as well as to that of the related distractor, creating competition for lexical selection. Activation decays rapidly at the lexical nodes unless it is reinforced via connections to conceptual nodes of related words; an unrelated distractor word is a less effective competitor than a related word, because its lexical node does not receive additional activation from its semantic cohort.

Interference is not usually found when categorically related words are presented as primes and targets, because word reading - unlike picture naming - is a wellpracticed task; it can be performed when overall levels of activation in the network are low. Furthermore, words activate their lexical representations directly. The result is that during simple word naming, activation at the conceptual level will be weak, failing to exceed the threshold that is required to reactivate the lexical nodes of related words and induce competition for selection. However, if activation throughout the network could somehow be increased, conceptual-level connections between related words could result in sustained activation - and, therefore, increased competition - at the lexical level. Wentura and Frings's (2005) task, which used long-duration but highly degraded primes, made prime processing very difficult. Because the rapid alternation of prime and mask created a flickering appearance and the target immediately followed the prime, participants could not rely on an exogenous cue to signal the onset of the target; they needed to pay close attention to the prime in order to ascertain when the target appeared. In a connectionist model, increased attention to both prime and target could result in increased overall activation (from task nodes associated with both prime and target lexical nodes) in the network. This increased activation causes the prime's lexical node to stay active longer. Then, when the target's lexical node is activated, spreading activation from the lexical to conceptual level would exceed the threshold and continue to activate the lexical node that is associated with the related prime. This 
extended activation of the prime's lexical node results in lexical-level competition-and, thus, interference-in target naming.

The above argument implies that other tasks could be designed to produce reliable semantic interference between words, as long as those tasks required increased effort to process the prime while displaying it for a sufficient duration. Embedding the prime words in a rapid serial visual presentation (RSVP) series may have such an effect. In RSVP, words are typically displayed for about $100 \mathrm{msec}$, with each word replacing the previous word at fixation; this means that each word (other than the initial word) is both forward- and backward-masked (the final word is often followed by a symbol string). Forward masking disrupts information that is required to correctly identify the word, whereas backward masking interferes with access to conscious awareness (Breitmeyer, 1984; Enns \& Di Lollo, 2000). Reporting a prime word embedded in an RSVP stream is therefore much more attention demanding than reporting a prime word with the same exposure duration shown in isolation.

In Experiments 1 and 2 of the present study, primes were presented as the third word in a series of three words that were displayed in RSVP. Attention to the prime was encouraged by postcuing participants to report the RSVP words on some trials. On the remaining trials, a target word appeared in a red font following the RSVP stream, and participants were asked to name it as quickly and accurately as possible. In Experiment 1, a repetition blindness manipulation was included to further increase the difficulty of prime processing. Repetition blindness (Kanwisher, 1987) refers to the finding that the second of two orthographically similar words shown in close proximity in an RSVP stream often fails to be reported.

\section{EXPERIMENTS 1A AND 1B}

Experiment 1A investigated interference between category coordinate prime-target pairs, with the prime displayed as the third word in an RSVP series. This presentation method made it possible to display the prime for 80-100 msec, yet still made prime processing difficult. Many trials required report of the RSVP words in order to encourage attention to the primes. On some trials in Experiment 1, the first word in the RSVP stream shared letters with the third (prime) word, e.g., BIRTH and birch. Because it is more difficult to report orthographically similar RSVP words, the inclusion of a number of these trials may further increase participants' attentional effort toward prime processing. Experiment $1 \mathrm{~B}$ used the same procedures as those in Experiment 1A, but the stimuli were associates rather than categorically related words.

\section{Method}

Participants. Sixty undergraduates at Iowa State University participated in Experiment 1A for course credit; an additional 60 undergraduates participated in Experiment 1B. All were native English speakers. In each experiment, two participants were removed from the analysis because of an excessive error rate on naming trials (repeated failures to trigger the voice key). They were replaced with additional participants.

Design and Materials. For Experiment 1A, 48 semantically related but nonassociated prime-target pairs were adapted from Chiarello, Burgess, Richards, and Pollock (1990). The pairs were category coordinates, such as table-bed and ear-foot. Both the forward and backward associative strengths for these pairs had means of .01 (Nelson, McEvoy, \& Schreiber, 1998). For Experiment 1B, we used 48 associated but not categorically related prime-target pairs that were also adapted from Chiarello et al. (1990). The mean forward associative strength for these pairs was .26; mean backward strength was .14.

Examples of the six stimulus conditions in Experiments 1A and $1 \mathrm{~B}$ are shown in Table 1. In the RB-related condition, the first word in the RSVP sequence shared several letters with the prime, and the naming target was a category coordinate (Experiment $1 \mathrm{~A}$ ) or associate (Experiment 1B) of the prime. Because there was orthographic overlap between the first and third words in the RSVP series, RB could occur on some proportion of the RB-related trials. The nonRB-related condition was created from the RB-related condition by changing the first word to an orthographically nonsimilar word that was matched in frequency to the first word from the RB-related condition. The two unrelated conditions were created by changing the prime to a word unrelated to the naming target, but matched in frequency to the related prime. ${ }^{1}$ Related and unrelated primes were matched in length and were similar in frequency (see Appendix A for frequencies, normed naming times, and normed lexical decision times for prime and target stimuli).

In both experiments, RB and non-RB full report trials were created from the RB- and non-RB-related trials by omitting the naming target. Filler trials with all nonsimilar words were created so that the proportion of trials containing orthographically similar words in the full report trials was the same as that in the naming trials $(25 \%)$. Six stimulus lists were created in each experiment in order to counterbalance the presentation of the stimuli across participants; each participant viewed 32 full report trials (16 RB and 16 non-RB) and 32 naming trials.

Procedure. Stimuli for all experiments were presented on a Macintosh G4, with the display controlled by the PsyScope experimental control software. Participants were seated in front of a computer monitor and a microphone that was connected to a PsyScope button

Table 1

Examples of Stimulus Sets From Experiments 1A and 1B

\begin{tabular}{llllll}
\hline & \multicolumn{2}{c}{$\begin{array}{c}\text { Experiment 1A: } \\
\text { Category Coordinates }\end{array}$} & & \multicolumn{2}{c}{$\begin{array}{c}\text { Experiment 1B: } \\
\text { Associates }\end{array}$} \\
\cline { 2 - 3 } \cline { 5 - 6 } \multicolumn{1}{c}{ Condition } & RSVP Sequence & Target & & RSVP Sequence & Target \\
\hline RB-related & BIRTH copy birch & ELM & & CRAZY house cradle & BABY \\
Unrelated control & BIRTH copy trash & ELM & & CRAZY house insult & BABY \\
Non-RB-related & SWEET copy birch & ELM & & SENIOR house cradle & BABY \\
Unrelated control & SWEET copy trash & ELM & & SENIOR house insult & BABY \\
RB-FR & BIRTH copy birch & N/A & & CRAZY house cradle & N/A \\
Non-RB-FR & SWEET copy birch & N/A & & SENIOR house cradle & N/A \\
\hline
\end{tabular}

Note-RB, repetition blindness; FR, full report. 
Table 2

Mean Response Latencies (in Milliseconds) and Mean Percentage Error (Shown in Parentheses) on Naming Trials in Experiments $1 \mathrm{~A}$ and $1 \mathrm{~B}$

\begin{tabular}{lccccc}
\hline & \multicolumn{2}{c}{$\begin{array}{c}\text { Experiment 1A: } \\
\text { Category Coordinates }\end{array}$} & & \multicolumn{2}{c}{$\begin{array}{c}\text { Experiment 1B: } \\
\text { Associates }\end{array}$} \\
\cline { 2 - 3 } \cline { 5 - 6 } Condition & Non-RB & RB & & Non-RB & RB \\
\hline Unrelated & $603(2.5)$ & $599(3.5)$ & & $568(3.5)$ & $569(4.4)$ \\
Related & $618(2.5)$ & $619(3.1)$ & & $551(2.5)$ & $555(4.0)$ \\
Difference & -15 & -20 & & +17 & +14 \\
$S E^{*}$ & 10 & 9 & & 7 & 11 \\
\hline
\end{tabular}

Note-RB, repetition blindness. ${ }^{*}$ Standard error of the difference.

box (New Micros, Dallas, TX). Unless otherwise noted, stimuli were displayed in black Chicago 36-point font on a light gray background. Each trial began with a row of asterisks displayed in the center of the computer screen for $750 \mathrm{msec}$, followed by a 500-msec blank interval. Three words were then displayed in RSVP for 79-102 msec each (exposure duration was set individually on the basis of a practice procedure that will be described later). The first of the RSVP words was displayed in uppercase letters; the other two words were displayed in lowercase. The RSVP series was followed immediately by a mask of seven ampersands. Full report and naming trials were intermixed randomly by the computer for each participant. On full report trials, the mask was displayed for $250 \mathrm{msec}$ and was followed by a blue question mark as a cue to report the RSVP series. After the participant reported the words, the experimenter coded in the response using keys to designate whether the participant correctly reported the first and third RSVP words (scored separately). The next trial began immediately after the responses were recorded. On naming trials, the RSVP series was followed by a mask displayed for $500 \mathrm{msec}$, which in turn was followed by a blank interval of another $500 \mathrm{msec}$. The naming target then appeared in all red, uppercase letters. The stimulus onset asynchrony (SOA) between the prime and the naming target was therefore a little over 1,000 msec. In Experiments $1 \mathrm{~A}$ and $1 \mathrm{~B}$, we chose a long SOA in order to avoid confusion as to which item (prime or target) was to be named. The naming target was erased from the screen once the voice key was triggered. The next trial began after 1,000 msec.

A series of practice trials, during which exposure duration for the RSVP words was gradually decreased from 161 to $91 \mathrm{msec}$, preceded the experimental trials. Exposure duration for the experimental trials was set as the shortest exposure at which participants were able to report both the first and third RSVP words at least $50 \%$ of the time (all practice trials were non-RB trials). Participants scoring well above $50 \%$ on the $91-\mathrm{msec}$ duration were run at $79 \mathrm{msec}$ for the experimental trials. Mean exposure duration across participants was $87 \mathrm{msec}$ for both Experiments $1 \mathrm{~A}$ and $1 \mathrm{~B}$.

\section{Results and Discussion}

In Experiment $1 \mathrm{~A}$, the prime was correctly reported $75 \%$ of the time in the non-RB condition and $52 \%$ of the time in the RB condition, representing a significant $\mathrm{RB}$ effect $\left[F_{1}(1,59)=41.06 ; F_{2}(1,47)=31.62\right.$; both $p$ s $\left.<.001\right]$. Results were similar to those in Experiment 1B; the prime was correctly reported $71 \%$ of the time in the non-RB condition and $47 \%$ of the time in the RB condition-again, a significant difference $\left[F_{1}(1,59)=68.38 ; F_{2}(1,47)=\right.$ 30.99; both $p$ s $<.001]$.

Mean naming latencies and error rates for Experiments $1 \mathrm{~A}$ and $1 \mathrm{~B}$ are shown in Table 2. Trials containing incorrect responses, equipment malfunctions, or latencies below $200 \mathrm{msec}$ or above 2,000 msec were excluded from the analysis. No significant effects were observed in the error analyses for either experiment.

For the response latencies, in Experiment 1A, a $2 \times 2$ repeated measures ANOVA revealed a significant semantic interference effect, with related targets named $18 \mathrm{msec}$ slower than unrelated $\left[F_{1}(1,59)=5.56 ; F_{2}(1,47)=4.31\right.$; both $p \mathrm{~s}<.05]$. There were no other effects or interactions (all $F \mathrm{~s}<1$ ), suggesting that the interference effect was of similar magnitude for the RB and non-RB conditions. In Experiment $1 \mathrm{~B}$, analysis revealed a significant associative facilitation effect $\left[F_{1}(1,59)=4.26 ; F_{2}(1,47)=4.97\right.$; both $p$ s $<.05$ ]. Again, there were no other main effects or interactions (all $F \mathrm{~s}<1$ ).

The results of Experiment 1A demonstrate that semantic interference can be obtained in a word-naming task under certain conditions: The primes and targets must be categorically related, the participants must attend to the primes, and the task must be made difficult. Degrading the primes, requiring participants to attend to them (in preparation for naming them on some trials), and requiring speeded target naming produces a "task set" that serves to increase overall activation in the naming network. The elevated activation spreading to the conceptual level increases the influence of semantic relatedness on word naming. The results of Experiment 1B suggest that the RSVP procedure does not produce interference unless the primes and targets are categorically related, since no interference was found for associatively related stimuli.

Experiments 1A and 1B were conducted between participants, and-as can be seen in Table 2-naming latencies were faster overall for Experiment 1B. Experiment 2, therefore, contrasted both types of relations (category coordinates and associates) within a single experiment.

\section{EXPERIMENT 2}

Experiment 2 attempted to replicate the dissociation between interference for category coordinates and facilitation for associates using a within-subjects design. In addition, SOA was manipulated between subjects to investigate the time course of the effects. RB trials were omitted from Experiment 2 so that we could determine whether they are necessary to obtain the semantic interference effect.

\section{Method}

Participants. A total of 192 undergraduates at Iowa State University participated for course credit. All were native English speakers.

Table 3

Percentage Correct Report of Prime on Full-Report Trials in Experiment 2

\begin{tabular}{lcccc}
\hline & \multicolumn{4}{c}{ SOA (msec) } \\
\cline { 2 - 5 } \multicolumn{1}{c}{ Condition } & 687 & 887 & 1,087 & 1,287 \\
\hline Category coordinates & 74 & 67 & 67 & 68 \\
Associates & 66 & 61 & 64 & 63 \\
\hline
\end{tabular}

Note-Only related primes appeared in full-report trials. SOA, stimulus onset asynchrony. Standard errors for all conditions ranged from 3\% to $4 \%$. 
Two participants were removed from the analysis and replaced with additional participants because of an excessive error rate on naming trials.

Design and Materials. Materials from Experiments $1 \mathrm{~A}$ and $1 \mathrm{~B}$ were combined into a single experiment. The design was $4 \times 2 \times 2$, with four levels of SOA $(687,887,1,087$, and 1,287 msec) as a between-subjects factor, and two levels of relatedness (related and unrelated) and two levels of stimulus type (category coordinates, associates) as within-subjects factors.

Procedure. The procedure was the same as that in Experiment 1, except that exposure durations for the RSVP words were kept constant at $87 \mathrm{msec}$, and no RB trials were included.

\section{Results and Discussion}

The percentage-correct report of the prime (on fullreport trials) for each condition is shown in Table 3. Prime report was $6 \%$ higher for the category coordinate primes than for the associates; this difference was significant in the subjects analysis $[F(1,188)=31.28, p<.001]$, but only marginally significant in the items analysis $[F(1,94)=$ $3.24, p=.075]$. The effect of SOA was nonsignificant by subjects $(F<1)$, but significant by items $[F(3,282)=$ $6.27, p<.001]$. The prime type $\times$ SOA interaction was nonsignificant (both $F_{\mathrm{s}}<1$ ).

Mean naming latencies and error rates for Experiment 2 are shown in Table 4. No significant effects were observed in the error analyses. Analyses of response latencies revealed that the interaction between relatedness and stimulus type was significant in both the subjects and items analyses $\left[F_{1}(1,188)=12.74, p<.001 ; F_{2}(1,94)=\right.$ $9.61, p<.01]$. The triple interaction (stimulus type, relatedness, and SOA) was significant in the subjects analysis $\left[F_{1}(3,188)=2.69, p<.05\right]$ and marginal in the items analysis $\left[F_{2}(3,282)=2.10, p=.10\right]$. No other effects were significant. ${ }^{2}$

Planned comparisons indicated that the interference effect for category coordinates was significant at the $687-$ msec SOA $\left[F_{1}(1,47)=9.41, p<.01 ; F_{2}(1,47)=\right.$ $4.52, p<.05]$, as was the facilitation effect for associates $\left[F_{1}(1,47)=5.78 ; F_{2}(1,47)=4.44\right.$; both $p$ s $\left.<.05\right]$. At the 887-msec SOA, the interference effect was significant in the subjects analysis $\left[F_{1}(1,47)=5.01, p<.05\right]$, with a trend toward significance in the item analysis $\left[F_{2}(1,47)=\right.$

Table 4

Mean Response Latencies (in Milliseconds) and Mean Percentage Error (Shown in Parentheses) on Naming Trials in Experiment 2

\begin{tabular}{lcccc}
\hline & \multicolumn{4}{c}{ SOA (msec) } \\
\cline { 2 - 5 } \multicolumn{1}{c}{ Condition } & 687 & 887 & 1,087 & 1,287 \\
\hline Category Coordinates & & & & \\
$\quad$ Unrelated & $580(5.8)$ & $576(5.1)$ & $565(5.4)$ & $560(5.7)$ \\
Related & $594(6.5)$ & $586(4.8)$ & $572(4.8)$ & $561(5.6)$ \\
Difference & -14 & -10 & -7 & -1 \\
$S E^{\dagger}$ & 4 & 5 & 4 & 5 \\
Associates & & & & \\
$\quad$ Unrelated & $583(5.5)$ & $576(5.2)$ & $566(5.5)$ & $556(5.4)$ \\
Related & $571(5.3)$ & $571(5.8)$ & $565(5.8)$ & $557(5.2)$ \\
Difference & +12 & +5 & +1 & -1 \\
SE* & 6 & 4 & 5 & 5 \\
\hline
\end{tabular}

Note-SOA, stimulus onset asynchrony. ${ }^{*}$ Standard error of the difference.
$2.72, p=.11]$. No other effects were significant. Thus, Experiment 2 replicated the findings from Experiments 1A and $1 \mathrm{~B}$ of interference for category coordinates and facilitation for associates, with both effects diminishing with increasing SOA.

It is important for one to consider an alternative explanation for our results: Because our prime words differed for associatively related versus categorically related stimuli, it is possible that the differing effects (facilitation vs. interference) were driven by differences in prime difficulty, even though related and unrelated primes were equated for frequency and length. Accordingly, we examined naming and lexical decision time norms (Balota et al., 2002) for all prime words; no significant differences were found in naming or lexical decision times for related and unrelated primes (all $F \mathrm{~s}<1$; see Appendix A for means).

We have suggested that it is necessary to make prime processing difficult while requiring attention to the primes in order to demonstrate semantic interference between word primes and targets. To confirm this, we conducted two follow-up experiments using the stimuli from Experiments 1 and 2, without the RSVP procedure. There were 36 participants in each experiment. The first was a standard prime-target naming study in which the prime was displayed for $87 \mathrm{msec}$ and the target followed with an SOA of 287, 687, or 1,087 msec. The second follow-up experiment was the same as the first except that on some trials, the prime had to be named instead of the target. Accuracy of prime report ranged from $94 \%$ to $98 \%$ correct across conditions.

No interference was found in either experiment; indeed, in a combined analysis with the factors experiment, stimulus type, relatedness, and SOA, we found the expected main effect of relatedness $[F(1,66)=8.17, p<.01]$ that was not qualified by an interaction with stimulus type $(F<1)$, indicating a small amount of facilitation across both category coordinates and associates (see Appendix B for mean response latencies, error rates, and results of statistical tests). The results of these follow-up experiments provide further support for the argument that interference for category coordinates will only be found when prime processing is made sufficiently attention demanding. Merely requiring participants to name the primes is not sufficient; when prime processing is too easy (as in our follow-up experiments), interference is not observed.

\section{GENERAL DISCUSSION}

These experiments used a novel prime-target technique to investigate semantic interference effects in word naming. In both experiments, participants were instructed to silently read and prepare to name a series of words shown in RSVP; if a word in red followed the RSVP series, they were to name that word instead. The last word in the RSVP series served as the prime for the red target word. Semantic interference was obtained when the prime and target were categorically related (Experiments $1 \mathrm{~A}$ and 2); in contrast, associatively related primes and targets produced facilitation (Experiments 1B and 2). 
One possible explanation for these results can be illustrated by examining the way words are used in the context of a sentence. Categorically related words are often described as sharing semantic features (e.g., Alario, Segui, \& Ferrand, 2000); however, they also can be described as being contextually similar in that one can be substituted for another in a number of contexts without creating an implausible statement (Miller \& Charles, 1991). Such interchangeability is expected to lead to lexical competition, since only one of a number of plausible words could be selected to fill a particular contextual slot at any one time. In contrast, associated words such as mouse and cheese do not typically compete for the same slot in a sentence.

A discrepancy between Experiments 1A and 2 is that the interference effect was found at an SOA of 1,087 msec in Experiment 1A (which included RB trials), but only at the shortest SOA $(687 \mathrm{msec}$ ) in Experiment 2 (which did not include RB trials). The requirement that prime processing must be attention demanding in order to demonstrate interference provides an explanation for this discrepancy. It is possible that in Experiment 1A (and 1B), participants attempted to compensate for the increased difficulty of the RB trials by further increasing their attention to the primes. The increased attentional effort would, in turn, be expected to magnify the interference effect, enabling it to be detected at a longer SOA. This compensation would not be required in Experiment 2, which had no RB trials.

It appears as if RB (or some other method of prime degradation) is needed to produce larger interference effects. In addition, our RSVP procedure has some advantages when compared with picture-word interference paradigms. Many concepts aren't easily depicted in a drawing or photograph; this fact limits the types of semantic relations that can be investigated using picture-word interference. The use of words as both primes and targets also obviates the need for a familiarization phase (often required in picture-word interference studies) wherein target names are practiced. Although the interference effects we obtained were smaller than those usually found in picture-word interference studies, they were demonstrated using a much longer SOA between prime and target. We suggest that semantic effects are prolonged with the RSVP procedure because of the higher level of activation engendered by prime degradation and the need to report the RSVP words on some trials. It may be possible to further increase the size of the interference effect by using a somewhat shorter SOA and by degrading the target, as well as the prime.

\section{AUTHOR NOTE}

Correspondence concerning this article should be addressed to A. L. Morris, Department of Psychology, W112 Lagomarcino, Iowa State University, Ames, IA 50011-3180 (e-mail: almorris@iastate.edu).

Note-Accepted by David A. Balota's editorial team.

\section{REFERENCES}

Alario, F. X., Segui, J., \& Ferrand, L. (2000). Semantic and associative priming in picture naming. Quarterly Journal of Experimental Psychology, 53A, 741-764.

Balota, D. A., Cortese, M. J., Hutchison, K. A., Neely, J. H., Nelson, D., Simpson, G. B., \& Treiman, R. (2002). The English Lexicon Project: A web-based repository of descriptive and behavioral measures for 40,481 English words and nonwords. Retrieved July 30, 2006, from elexicon.wustl.edu/.

Bloem, I., \& LA HeIJ, W. (2003). Semantic facilitation and semantic interference in word translation: Implications for models of lexical access in language production. Journal of Memory \& Language, 48, 468-488.

Bloem, I., van den Boogaard, S., \& La HeiJ, W. (2004). Semantic facilitation and semantic interference in language production: Further evidence for the conceptual selection model of lexical access. Journal of Memory \& Language, 51, 307-323.

BREITMEYER, B. (1984). Visual masking: An integrative approach. New York: Oxford University Press.

Chiarello, C., Burgess, C., Richards, L., \& Pollock, A. (1990). Semantic and associative priming in the cerebral hemispheres: Some words do, some words don't ... sometimes, some places. Brain \& Language, 38, 75-104.

ENNS, J. T., \& Di LoLlo, V. (2000). What's new in visual masking? Trends in Cognitive Sciences, 4, 345-352.

FRANCIS, W. N., \& KUČERA, H. (1982). Frequency analysis of English usage: Lexicon and grammar. Boston: Houghton Mifflin.

Hutchison, K. A. (2003). Is semantic priming due to association strength or featural overlap? A microanalytic review. Psychonomic Bulletin \& Review, 10, 785-813.

KANWISHER, N. (1987). Repetition blindness: Type recognition without token individuation. Cognition, 27, 117-143.

Lucas, M. (2000). Semantic priming without association: A metaanalytic review. Psychonomic Bulletin \& Review, 7, 618-630.

Miller, G. A., \& Charles, W. G. (1991). Contextual correlates of semantic similarity. Language \& Cognitive Processes, 6, 1-28.

NeELY, J. H. (1991). Semantic priming effects in visual word recognition: A selective review of current findings and theories. In D. Besner \& G. W. Humphreys (Eds.), Basic processes in reading: Visual word recognition (pp. 264-336). Hillsdale, NJ: Erlbaum.

Nelson, D. L., McEvoy, C. L., \& Schreiber, T. A. (1998). The University of South Florida word association, rhyme, and word fragment norms. Retrieved April 30, 2006, from www.usf.edu/FreeAssociation/.

Perea, M., \& Gotor, A. (1997). Associative and semantic priming effects occur at very short stimulus-onset asynchronies in lexical decision and naming. Cognition, 62, 223-240.

Starreveld, P. A., \& LA HeI, W. (1996). Time-course analysis of semantic and orthographic context effects in picture naming. Journal of Experimental Psychology: Learning, Memory, \& Cognition, 22, 896-918.

WENTURA, D., \& FRINGS, C. (2005). Repeated masked category primes interfere with related exemplars: New evidence for negative semantic priming. Journal of Experimental Psychology: Learning, Memory, \& Cognition, 31, 108-120.

\section{NOTES}

1. Note that repetition blindness would only be expected in the RBrelated condition; it would not be expected in the corresponding unrelated condition.

2. $F$ values for nonsignificant results are as follows: main effect of relatedness $\left[F_{1}(1,188)=1.15 ; F_{2}<1\right]$. Main effect of stimulus type $\left[F_{1}(1,188)=10.35 ; F_{2}<1\right]$. Main effect of SOA $\left[F_{1}<1 ; F_{2}(3,282)=\right.$ 29.748]. Relatedness $\times$ SOA and stimulus type $\times$ SOA interactions (all $F$ s $<1$ ). SOA was manipulated between subjects, whereas stimulus type was manipulated between items. 


\section{APPENDIXA}

Table A1

Mean Frequency (per Million), Normed Naming Times

(in Milliseconds), and Normed Lexical Decision Times (in Milliseconds) for Primes and Targets

\begin{tabular}{|c|c|c|c|c|c|}
\hline & \multirow[b]{2}{*}{ Frequency } & \multicolumn{2}{|c|}{ Naming Norms } & \multicolumn{2}{|c|}{$\begin{array}{c}\text { Lexical } \\
\text { Decision Norms }\end{array}$} \\
\hline & & RT & $z$ Score & RT & $z$ Score \\
\hline \multicolumn{6}{|l|}{ Category Coordinates } \\
\hline Unrelated primes & 38 & 613 & -0.51 & 631 & -0.56 \\
\hline Related primes & 35 & 611 & -0.51 & 624 & -0.59 \\
\hline Targets & 49 & 605 & -0.53 & 602 & -0.64 \\
\hline \multicolumn{6}{|l|}{ Associates } \\
\hline Unrelated primes & 34 & 615 & -0.50 & 627 & -0.57 \\
\hline Related primes & 34 & 610 & -0.51 & 632 & -0.56 \\
\hline Targets & 46 & 599 & -0.58 & 587 & -0.71 \\
\hline
\end{tabular}

Note-Mean word frequencies were obtained from Francis and Kučera (1982).

\section{APPENDIX B}

Table B1

Mean Response Latencies (in Milliseconds) and Mean Percentage Error (Shown in Parentheses) on Naming Trials in Follow-Up Experiments

\begin{tabular}{|c|c|c|c|c|c|c|}
\hline \multirow[b]{3}{*}{ Condition } & \multicolumn{6}{|c|}{ SOA } \\
\hline & \multicolumn{3}{|c|}{ Name Target Only } & \multicolumn{3}{|c|}{ Name Prime or Target } \\
\hline & 287 & 687 & 1,087 & 287 & 687 & 1,087 \\
\hline \multicolumn{7}{|c|}{ Category Coordinates } \\
\hline Unrelated & $496(4)$ & $482(2)$ & $526(2)$ & $615(4)$ & $591(4)$ & $588(2)$ \\
\hline Related & $492(4)$ & 477 (3) & $527(4)$ & $602(3)$ & $583(3)$ & $585(3)$ \\
\hline Difference & +4 & +5 & -1 & +13 & +8 & +3 \\
\hline$S E^{*}$ & 4 & 5 & 7 & 8 & 9 & 8 \\
\hline \multicolumn{7}{|l|}{ Associates } \\
\hline Unrelated & $493(3)$ & $475(5)$ & $513(2)$ & $607(3)$ & $590(5)$ & $585(3)$ \\
\hline Related & $486(2)$ & $468(3)$ & $509(4)$ & $593(2)$ & $579(3)$ & $577(2)$ \\
\hline Difference & +7 & +7 & +4 & +14 & +11 & +8 \\
\hline$S E^{*}$ & 6 & 7 & 5 & 7 & 8 & 9 \\
\hline
\end{tabular}

Note-Stimulus onset asynchrony (SOA) was a between-subjects factor; there were 12 participants at each SOA. The main effect of relatedness was significant $[F(1,66)=8.17, p<$ $.01]$, as was the main effect of experiment $[F(1,66)=45.51, p<.001]$ and the main effect of stimulus type $[F(1,66)=12.62, p<.005]$. The experiment $\times$ SOA interaction was nonsignificant $[F(2,66)=1.25, p>.25]$, as was the experiment $\times$ relatedness interaction $[F(2,66)=$ $1.62, p>.20]$. All other $F$ s were $<1$. ${ }^{*}$ Standard error of the difference.

(Manuscript received August 26, 2005;

revision accepted for publication August 9, 2006.) 